\title{
Low Temperature Green Synthesis of Sulfur-Nitrogen Co- Doped Graphene as Efficient Metal-Free Catalysts for Oxygen Reduction Reaction
}

\author{
Yuan Zhao ${ }^{1}$, Chuanxiang Zhang ${ }^{2}$, Tong Liu ${ }^{1}$, Rong Fan ${ }^{1}$, Yao Sun ${ }^{1}$, Haijun Tao ${ }^{1}$, Jianjun Xue \\ ${ }^{1}$ College of Material Science and Science Technology, Nanjing University of Aeronautics and \\ Astronautics, Nanjing 211106, PR China \\ ${ }^{2}$ College of Materials Engineering, Nanjing Institute of Technology, Nanjing 211167, PR China \\ *E-mail: jjxue@nuaa.edu.cn
}

doi: $10.20964 / 2017.04 .67$

Received: 12 January 2017 / Accepted: 23 February 2017 / Published: 12 March 2017

\begin{abstract}
Development of inexpensive and scalable cathode catalysts that can efficiently catalyze the oxygen reduction reaction (ORR) is of significance in practical application of fuel cells. Heteroatom doped carbons have been recognized as the promising candidate. Herein sulphur-nitrogen co-doped reduced graphene oxide (S-N-rGO) was prepared through low-temperature refluxing with sodium sulfide, ammonia and graphene oxide as the precursors. The catalytic performance of the fabricated S-N-rGO towards the ORR was assessed by electrochemical test. The effect of reaction temperature on catalytic activity was also studied. The S-N-rGO gained under the reaction temperature of $150{ }^{\circ} \mathrm{C}(\mathrm{S}-\mathrm{N}-\mathrm{rGO}-$ $150{ }^{\circ} \mathrm{C}$ ) demonstrates higher electrocatalytic activity and mainly four electron ORR process in alkaline condition. In addition, it also shows improved durabity and better resistance toward methanol. The excellent performance for the ORR on S-N-rGO is attributed to the synergistic effect originating from the doped $\mathrm{S}$ and $\mathrm{N}$ in the graphene sheets.
\end{abstract}

Keywords: co-doped; graphene; oxygen reduction; electrocatalysis; durabity

\section{$\underline{\text { FULL TEXT }}$}

(C) 2017 The Authors. Published by ESG (www.electrochemsci.org). This article is an open access article distributed under the terms and conditions of the Creative Commons Attribution license (http://creativecommons.org/licenses/by/4.0/). 